\title{
THE PRE-ERUPTIVE ILLNESS OF MEASLES
}

BY

\author{
M. W. PARTINGTON* and J. F. P. QUINTON \\ From the Jenny Lind Children's Hospital, Norwich
}

(RECEIVED FOR PUBLICATION SEPTEMBER 11, 1958)

According to Sydenham (1717), the rash of measles appears on the fourth, or sometimes the fifth, day of the illness. This has remained the standard teaching of most of the authorities on infectious diseases and paediatrics (e.g. Sheldon, 1948; Banks, 1949; Harries and Mitman, 1951; Top, 1955). However, Panum (1847), in his classic report of a measles epidemic, states that although the prodromal illness usually lasts two to four days it can last up to eight days. Some modern writers agree and allow that on occasion the prodromal illness may be as long as six to eight days (e.g. Joe, 1947; Stimson and Hodes, 1956; Ellis, 1956). Recently Christensen, Schmidt, Bang, Andersen, Jordal and Jensen (1953), observing a very similar epidemic in Southern Greenland to that described by Panum in the Faroe Islands, also found that the prodromal illness may be as long as eight days. Two cases with a prodromal illness lasting nine and 11 days respectively were recorded by Selby (1936), and Spence, Walton, Miller and Court (1954), in their 1,000-family survey, found two patients who were ill throughout the incubation period.

A relatively unknown feature of the pre-eruptive period of measles is the 'illness of infection', first described by Goodall (1925). Despite at least 25 cases reported in the literature (Erdheim, 1926; Abercrombie, 1929; Meyer and Greenthal, 1930; Smith, 1944), and a reasonable theoretical basis (Grist, 1950), it has received scant attention.

* Present address: The Department of Child Health, University of Sheffield.
Personal observation suggested that both a long prodromal illness and the illness of infection are not at all uncommon in measles and so we thought it of interest to review our own material.

\section{Methods and Material}

The case notes were scrutinized of all patients with the diagnosis of measles admitted to the Norwich Isolation Hospital between July 1, 1952, and April 1, 1958, and to the Jenny Lind Hospital between January 1, 1951, and April 1, 1958. A large proportion of these patients had been seen by one or both of us in the acute phase. Cases were allowed into the series if they satisfied the following conditions: (1) The patient was thought to have measles by the physician in charge of the case at the time. (2) There were reasonably precise indications in the case notes of the time of onset of the illness (e.g. 'Ten days ago ...', 'A week ago ....', a definite date or fever on a temperature chart). (3) There were equally clear indications of the day an unmistakable measles rash appeared. (4) The patient had both fever and a morbilliform rash. (5) Each patient had in addition at least one of the following: (a) Koplik's spots, (b) conjunctivitis, (c) respiratory catarrh.

Over 120 case notes were available and 82 fulfilled these requirements.

\section{Results}

Table 1 shows the cases distributed according to the day of the illness on which the morbilliform rash

TABLE 1

CASES DISTRIBUTED ACCORDING TO THE DAY OF THE ILLNESS ON WHICH THE MEASLES RASH CAME OUT

\begin{tabular}{|c|c|c|c|c|c|c|c|c|c|c|c|c|c|c|c|c|c|}
\hline \multirow{3}{*}{$\begin{array}{l}\text { Day of illness . } \\
\text { Number of cases }\end{array}$} & & \multicolumn{7}{|c|}{ Group I } & \multicolumn{9}{|c|}{ Group II } \\
\hline & $\ldots$ & 1 & 2 & 3 & 4 & 5 & 6 & 7 & 8 & 9 & 10 & 11 & 12 & 13 & 14 & 15 & 16 \\
\hline & $\ldots$ & 0 & 5 & 14 & 7 & 9 & 16 & 6 & 3 & 4 & 5 & 3 & 1 & 3 & 3 & 1 & 2 \\
\hline & & \multicolumn{7}{|c|}{57} & \multicolumn{9}{|c|}{25} \\
\hline
\end{tabular}


appeared. In 35 patients the rash had come out on or before the fifth day and by the end of the week in another 22. These cases have been called Group I. In the remaining 25 patients, nearly one-third of the series, the rash appeared on or after the eighth day of the illness, and these have been called Group II. Some general data on the whole series is shown in Tables 3, 4 and 5 .

Group I (57 cases). Nineteen patients in this group developed a measles rash on or before the third day of the illness.

Case 1. Glynn E., aged 22 months. Nine days previously his brother developed a measles rash. Day 1: Without warning he had a generalized convulsion and three further fits in the next two hours. On admission to hospital he was found to have fever, irritability, bilateral conjunctivitis, and Koplik's spots in each side of the mouth. Day 2: Characteristic measles rash appeared.

In 38 patients the rash came out on the fourth to the seventh day of illness.

Case 2. Tanji B., a girl, aged 4 years. In contact with measles at school. Day 1: Became irritable with a fever of $104^{\circ} \mathrm{F}$. and an inflamed throat. Day 2-3 : Passed eight watery stools with much mucus. Day 4: Onset of cough. Day 5: Began to vomit with her cough. Admitted to hospital and found to have fever, a running nose, injected fauces, a harsh cough and many palpable cervical glands. Day 6: Koplik's spots and a measles rash appeared. Her sister, admitted with her, also developed measles.

Group II (25 cases). In this group the measles rash appeared on or after the eighth day of the illness. The group can be sub-divided into $(a)$ those in whom the pre-eruptive illness was a long, continuous, but otherwise characteristic, prodromal illness (17 cases), and (b) those in whom the illness was diphasic (eight cases). Case 3 is an example of the first kind of illness.

Case 3. Jennifer W., aged 5 years. In contact with measles at school. Day 1-6: Developed a persistent cough. Day 7-11: Stayed away from school, had a runny nose, complained of episodic abdominal pain, was off her food and vomited several times. Day 12: Conjunctivitis, photophobia and fever. Day 13: Rash noticed in the morning which faded. Day 14: Rash reappeared. Admitted to hospital with fever, misery, conjunctivitis, confluent morbilliform rash on the face and upper trunk, injected fauces, enlarged cervical glands and rapid breathing.

The next patient's illness lasted 14 days before the measles rash came out. The illness was severe at the onset, then remitted, although it did not subside completely, and again became severe a few days before the rash appeared.
Case 4. Doreen B., aged 6 years. Day 1-3: Cough, fever and vomiting diagnosed as influenza. Day 4-11: Better, but still had anorexia, malaise and a cough. Day 12-13: Started to vomit again, was feverish and apathetic. Day 14: Admitted to hospital. Found to have fever, a loose cough, enlarged cervical glands and rales at both lung bases. Day 15: Widespread measles rash.

In eight patients in this group the pre-eruptive illness was diphasic with a distinct period of apparently normal health separating the first phase from the second.

Case 5. Susan B., aged 2 years. Two weeks previously admitted to hospital with bronchopneumonia which responded to treatment with penicillin. In contact with measles in the ward. Day 1: Evening temperature of $100^{\circ} \mathrm{F}$. Day 2-5: Appeared in good health. Day 6-10: Slight malaise and fever. Day 11-13: Fever, rales at the left lung base: penicillin restarted. Day 14: Measles rash on face, limbs and trunk (Fig. 1).

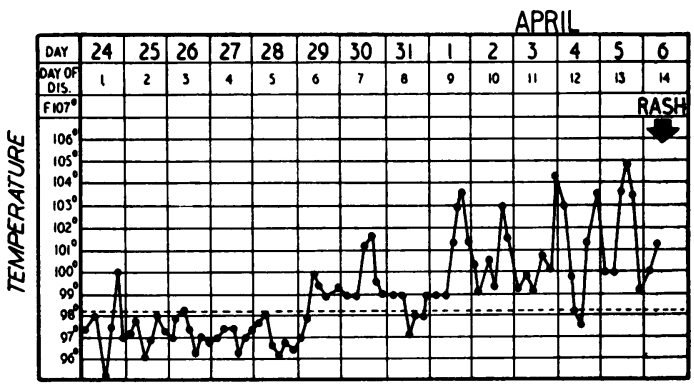

Fig. 1.-Temperature chart of Case 5 showing both a brief febrile illness of infection and a long prodromal illness.

In this last patient the first illness was no more than a spike of fever on a temperature chart, but in others it was more dramatic.

Case 6. James A., aged 4 years. Day 1-3: Anorexia, enlarged cervical glands and a 'pin-head' rash on the neck and behind the ears which spread to the trunk on Day 4. Day 5-8: Rash disappeared, felt completely well. Day 9: Malaise. Day 10: Conjunctivitis, running nose and a cough. Day 11: Measles rash on face and trunk. Day 14: Admitted to hospital with an extensive morbilliform rash, Koplik's spots, rhinorrhoea, a harsh cough and conjunctivitis.

Case 7. Christopher B., aged 5 years. Day 1-7: Developed a 'cold' with a loose cough and repeated vomiting. Day 8-9: Began to improve. Day 10-11: Up and about, apparently well. Day 12-13: Malaise. Day 14: Started vomiting again. Day 15: Admitted to hospital with fever, a loose cough, enlarged cervical glands, a nasal discharge, inflamed fauces and rales in the lungs. Day 16: Widespread measles rash. 
In Fig. 2 these seven cases are presented schematically. The histories are all reduced to the same time scale by assuming that in every case the interval between infection and the appearance of the rash is 14 days. Each case history is meant to represent a different type of pre-eruptive illness and the number of cases of each type in this series is shown in the figure. In Type 1 the rash comes out on or before the third day of the illness (or on the eleventh to the fourteenth day of the incubation period). In Type 2 the rash appears after four to seven days of illness and in Type 3 on or after the eighth day. In other words these three types form a series of increasingly long prodromal illnesses.

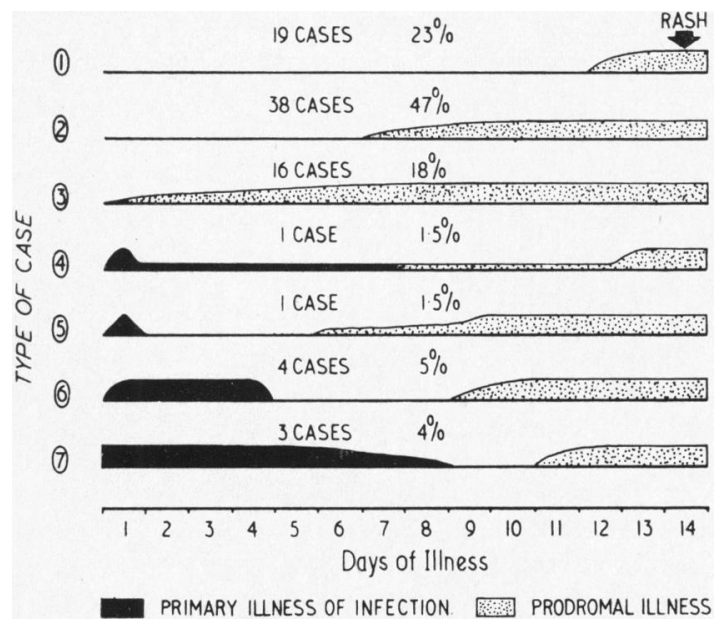

FIG. 2.-Schematic presentation of various types of pre-eruptive illness in measles. Number of cases of each type in this series is shown. Type 5 represents Case 5 (see Fig. 1 and text).

The fourth case may be regarded as a transitional type between those patients with a long prodromal illness and those with a distinct diphasic onset. The pre-eruptive illness lasted 14 days but it was severe at its onset then partially remitted and again became severe just before the rash came out.

The last three types of illness are all diphasic with an increasingly long first phase or primary illness of infection (Type 5 lasting one day, Type 6, two to four days and Type 7 longer than four days). These are associated with a shorter or longer second phase, prodromal illness (two to eight days) and a distinct intervening period of apparently normal health (two to four days).

Table 2 lists the clinical features of the illness of infection. Any of these may also be found in the prodromal illness. Although these two types of illness have been represented differently in Fig. 2
TABLE 2

CLINICAL FEATURES OF THE ILLNESS OF INFECTION

\begin{tabular}{|c|c|c|}
\hline Patient & Clinical Features & $\begin{array}{c}\text { Duration } \\
\text { (days) }\end{array}$ \\
\hline $\begin{array}{l}\text { S.B. } \\
\text { M.S. } \\
\text { S.C. } \\
\text { J.A. } \\
\text { W.E. } \\
\text { P.S. } \\
\text { C.B. } \\
\text { E.S. }\end{array}$ & 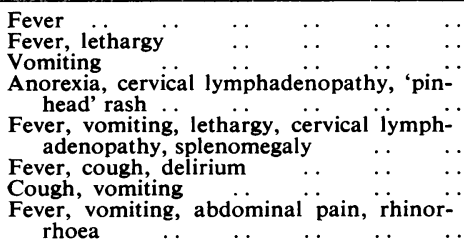 & $\begin{array}{l}1 \\
2 \\
3 \\
4\end{array}$ \\
\hline
\end{tabular}

it seems probable that the only essential differences between them are their severity and their timing in relation to the initial infection (see discussion).

Groups I and II were compared with regard to sex, age and year of onset. The differences in sex and age distribution (Tables 3,4) are not significant. Although fluctuations in the number of cases of measles occurred from year to year there was no obvious difference between the two groups in this respect (Table 5).

TABLE 3

SEX DISTRIBUTION

\begin{tabular}{|c|c|c|c|c|}
\hline & & Male & Female & Total \\
\hline $\begin{array}{l}\text { Group I } \\
\text { Group II }\end{array}$ & & $\begin{array}{l}31 \\
10\end{array}$ & $\begin{array}{l}26 \\
15\end{array}$ & $\begin{array}{l}57 \\
25\end{array}$ \\
\hline \multirow[t]{2}{*}{ Total } & $\ldots$ & 41 & 41 & 82 \\
\hline & & $\chi^{2}=0.92$ & $p=0.4$ & \\
\hline
\end{tabular}

TABLE 4

AGE DISTRIBUTION

\begin{tabular}{cc|ccc|c}
\hline & & \multicolumn{3}{|c|}{ Age (years) } & \\
\cline { 3 - 5 } & & $0-2$ & $3-5$ & $6+$ & Total \\
\hline Group I & $\ldots$ & 25 & 19 & 13 & 57 \\
Group II & $\cdots$ & 5 & 15 & 5 & 25 \\
\hline Total $\ldots$ & $\ldots$ & 30 & 34 & 18 & 82 \\
\hline & & $\chi^{2}=4 \cdot 46$ & $0 \cdot 2>p>0 \cdot 1$ & \\
\hline
\end{tabular}

TABLE 5

YEAR OF ONSET

\begin{tabular}{|c|c|c|c|c|c|c|c|}
\hline & \multicolumn{6}{|c|}{ Year of Onset } & \multirow[b]{2}{*}{ Total } \\
\hline & $1951 / 2$ & 1953 & 1954 & 1955 & 1956 & $1957 / 8$ & \\
\hline $\begin{array}{ll}\text { Group I } & \ldots \\
\text { Group II } & \ldots\end{array}$ & $\begin{array}{r}13 \\
8\end{array}$ & $\begin{array}{l}8 \\
1\end{array}$ & $\begin{array}{r}19 \\
8\end{array}$ & $\begin{array}{l}2 \\
3\end{array}$ & $\begin{array}{l}8 \\
3\end{array}$ & $\begin{array}{l}7 \\
2\end{array}$ & $\begin{array}{l}57 \\
25\end{array}$ \\
\hline Total & 21 & 9 & 27 & 5 & 11 & 9 & 82 \\
\hline
\end{tabular}




\section{Discussion}

This series shows a greater variation in the length of the pre-eruptive illness of measles than those reported by others. Thus Hermann (1914) found that in $84 \%$ of his patients the rash appeared on the third to the fifth day of illness. In the series reported by Christensen et al. (1953), the comparable figure is $66.7 \%$ whereas in our own it is $36.5 \%$.

In 17 patients (about $20 \%$ ) the rash came out on the eighth to the sixteenth day of continuous illness. Apart from a few of Christensen's patients whose rash appeared on the eighth day and the four patients cited previously (Selby, 1936; Spence et al., 1954), no comparable cases have been found in the literature.

Smith (1944) estimated that at least $10 \%$ of patients with measles have an illness of infection. Our figures (eight out of 82) agree well with this.

It cannot be claimed that this series is an unbiased sample of measles if only for the fact that all the cases were hospital admissions. This factor might possibly increase the likelihood of a long prodromal illness, but there is no way of assessing this from our data.

In an attempt to explain our results the patients with a diphasic onset and those with a long prodromal illness were grouped together and compared with the rest of the series. There were no significant differences in sex or age distribution or year of onset. This last finding suggests that the high frequency of a long pre-eruptive illness in this series was not due to a peculiar set of conditions obtaining in one particular epidemic.

Except for their duration the clinical features displayed by those patients with a prodromal illness longer than a week were no different from those usually described in measles. It has already been pointed out that the clinical features of the illness of infection (Table 2) are similar to those of the prodromal illness. Other workers have noted this similarity and even a morbilliform rash has been reported in the first phase (Goodall, 1925; and possibly Case 6 above). This may explain some relapses in measles and second attacks occurring within two or three weeks of the first (Smith, 1944).

Grist (1950) has applied the work of Burnet (1946) and Fenner (1948) to the pathogenesis of measles. It is suggested that after the initial infection, probably by way of the respiratory tract, the virus gains access to the blood stream and a viraemia ensues. After this invasion, which may take several days, the virus settles in the reticulo-endothelial system for the rest of the incubation period. Here it multiplies and then emerges in a second viraemia which is responsible for the customary clinical features of measles. It follows that if the first viraemia causes symptoms at all they might well be similar to those of the second phase illness; furthermore they might be less severe if only because the amount of circulating virus is less (Fenner, 1948). Our findings fit in well with this concept.

Fenner thought that this hypothesis might prove applicable to other acute infections. However, it is only in measles that an illness of infection has been clearly recognized. In poliomyelitis the onset is diphasic in $40 \%$ of cases with a minor illness followed by a period of health before the major illness develops (Russell, 1956). Whilst it is reasonably certain that the virus is present in the bloodstream at the time of the minor illness, it is not clear whether this corresponds with either Fenner's first or second viraemia.

Lymphocytic choriomeningitis may also have a diphasic onset. A minor illness with either influenzal or upper respiratory catarrhal features precedes the major illness by 10 days in at least $35 \%$ of patients (Adair, Gauld and Smadel, 1953). This could be an illness of infection. Clinically a similar diphasic onset may occur in sporadic, primary pyogenic meningitis. In a recent series of 74 cases we found that $18(25 \%)$ had a catarrhal or influenzal illness in the 10 days prior to the major illness with an intervening period of normal health.

It seems likely that many preceding minor illnesses are overlooked in these (and possibly other) diseases especially since the two phases of the illness are separated by a period of apparent health. Further work is needed to clarify these observations but it does seem reasonable to distinguish this kind of diphasic onset from that occurring in acute nephritis, rheumatic fever and acute disseminated encephalomyelitis where the continued presence of the infective organism is not necessary for the second phase illness to develop.

As Smith (1944) points out, it is really more surprising that 'the incubation of a virus in a body almost always occurs in a quiescent phase' than that symptoms should occur during this period. Our observations suggest that at least in measles the incubation period is less quiescent than is commonly supposed.

\section{Summary}

The onset of measles was studied in 82 patients. It was found that in 17 patients $(20 \%)$ the rash came out on the eighth to the sixteenth day of the illness. A further eight patients $(10 \%)$ had an illness of infection.

These findings are discussed. It is argued that there is little essential difference between the illness of infection and the prodromal illness except in 
time-relationship to the initial infection. This agrees with Fenner's (1948) hypothesis.

It is concluded that both an illness of infection and a long prodromal illness are commoner in measles than is usually reported.

We wish to thank Dr. R. M. Mayon-White and Professor R. S. Illingworth for criticizing the manuscript and Derek Martin of the Department of Medical Illustration, The Hospital for Sick Children, Great Ormond Street, for the figures. We should also like to thank the many house physicians at the Jenny Lind and Norwich Isolation Hospitals whose case notes contained enough information to make this study possible.

\section{REFERENCES}

Abercrombie, G. F. (1929). Brit. J. Child. Dis., 26, 15 Adair, C. V., Gauld, R. L. and Smadel, J. E. (1953). Ann. intern. Med., 39, 675.

Banks, H. S. (1949). The Common Infectious Diseases. Arnold, London.
Burnet, F. M. (1946). The Background of Infectious Diseases in Man. Melbourne Permanent Postgraduate Committee Melbourne. Christensen, P. E., Schmidt, H., Bang, H. O., Andersen, V., Jordal, B. and Jensen, O. (1953). Acta med. scand., 144, 430.

Ellis, R. W. B. (1956). Disease in Infancy and Childhood, 2 nd ed. Livingstone, Edinburgh.

Erdheim, S. (1926). Brit.J. Child. Dis., 23, 240.

Fenner, F. (1948). Lancet, 2, 915.

Goodall, E. W. (1925). Clin. J., 54, 69

Grist, N. R. (1950). Glasg. med. J., 31, 431.

Harries, E. H. R. and Mitman, M. (1951). Clinical Practice in Infectious Diseases, 4th ed. Livingstone, Edinburgh.

Herrman, C. (1914). Arch. Pediat.. 31, 885.

Joe, A. (1947). The Acute Infectious Fevers. Churchill, London. Meyer, P. R. and Greenthal, R. M. (1930). Arch. Pediat., 47, 399. Panum, P. L. (1847). Observations made during the Epidemic of Measles on the Faroe Islands in the Year 1846; Eng. trans. by A. S. Hatcher (1940). Published by Delta Omega Society, New York.

Russell, W. Kitchie (1956). Poliomyelitis, 2nd ed. Arnold, London. Selby, R. (1936). Brit. med. J., 1, 262.

Sheldon, W. (1948). Diseases of Children. Churchill, London.

Smith, R. E. (1944). Guy's Hosp. Rep., 93, 8.

Spence, J., Walton, W. S., Miller, F. J. W. and Court, S. D. M (1954). A Thousand Families in Newcastle upon Tyne. Oxford University Press, London.

Stimson, P. M. and Hodes, H. L. (1956). A Manual of the Common Contagious Diseases, 5 th ed. Kimpton, London.

Sydenham, T. (1717). The Whole Works of that Excellent Practical Physician, 7th ed. Wellington, London.

Top, F. H. (1955). Communicable Diseases, 3rd ed. Mosby, St. Louis. 